\title{
Six Focus Behaviors for Policymakers to Mitigate Climate Change
}

\author{
Kate Heller ${ }^{1}$, Michael Berger ${ }^{2}$, Antonius Gagern², Abdurakhim Rakhimov ${ }^{1}$, John Thomas ${ }^{2}$, and Erik \\ Thulin $^{1 *}$ \\ ${ }^{1}$ Center for Behavior \& the Environment, Rare \\ ${ }^{2}$ California Environmental Associates
}

\section{Summary:}

Policymakers have a crucial opportunity to help avert climate catastrophe with policies that promote emissions reductions. Policies informed by behavioral science principles that encourage individuals to reduce emissions can effectively complement broader top-down policies such as carbon pricing, provided they focus on those behaviors with the highest potential to reduce emissions. We conducted an analysis to identify behaviors that have the greatest practical potential to reduce emissions in the U.S. and modeled the impact of their uptake. Our analysis identifies six priority behaviors that, if adopted by $5-10 \%$ of the U.S. population, can lower current national emissions by 464 million tons of carbon dioxide equivalent per year (MtCO2e/year), or 7\% overall annually. We identify promising behavioral mechanisms that can inform policy design for each of these behaviors.

*Corresponding author: ethulin@rare.org

Acknowledgments: The authors thank Adam S. Levine, Lucia Reisch, and Erez Yoeli for their insightful comments and recommendations to the behavioral insights for policy section of this work.

Version $12 / 21 / 2020$ 


\section{Introduction}

Unless we take significant action to stem climate change, we are likely to face crop failure, extreme weather, rising seas, and heat-driven mortality. ${ }^{1}$ Policymakers have a crucial opportunity to help solve the climate crisis with policies that promote reducing or eliminating carbon emissions. In the United States, broad policies that would have substantial mitigation effects, such as pricing carbon emissions, currently face significant political opposition, making them unlikely to have the near-term effect on emissions needed to prevent the worst consequences of inaction. Policies that use behavioral science principles to encourage individual action while preserving choice have been shown to be effective and present a complementary path for policymakers to mitigate climate change. ${ }^{2,3}$ However, it is critical for policy development to prioritize an agenda of behaviors with the highest potential impact for emissions before proceeding to the development of policy solutions. ${ }^{4}$

Using a prioritization framework, we identified a shortlist of individual and household behaviors that have the greatest practical potential to reduce emissions in the U.S., due to their high impact on carbon emissions and U.S. relevance. Our analysis indicates that these six priority behaviors undertaken under an adoption assumption of 5 or $10 \%$ of the addressable market - the number of individuals or households that are in the position to, but have not yet adopted, a certain behavior - could lower current national emissions by an estimated $464 \mathrm{MtCO} 2 \mathrm{e} /$ year, or 7\% overall annually, and close our Paris Agreement shortfall by $76 \%$ by 2025 . Considering that U.S. emissions are projected to remain relatively flat through 2030, a 7\% reduction through individual and household behavior alone represents a non-trivial decrease. ${ }^{5}$

In addition to identifying these priority behaviors for policy intervention and quantifying the potential carbon impact of their adoption, we share examples from the literature of behavioral mechanisms that could inform policy design, as the first step towards policy development.

\section{Methods}

\section{Developing a Shortlist}

We reviewed several publications that estimated the carbon impact of emissions-reducing actions to generate a list of 55 possible interventions. ${ }^{6,7}$ (See Supplemental Materials for a full list of sources.) We focused our analysis on the United States, because it is the second-highest carbon-emitting country in the world, as well as one of the highest per-capita emitters, and because the current political gridlock presents a particularly strong opportunity for behaviorally informed policies rather than mandates.

We used two criteria to identify those behaviors best targeted by behaviorally informed U.S. policy. We first ranked each behavior's emissions reduction potential as high, medium, or low (H: $>500$ MtCO2e/year; M: 100-500 MtCO2e/year; L: <100 MtCO2e/year). We then conducted an initial literature review for the behaviors to understand the U.S. relevance of each intervention. We assessed each behavior's U.S. relevance using three criteria: (1) culturally feasible, (2) ecologically applicable, and (3) not disincentivized by existing regulatory frameworks or infrastructure. (Rankings available in Supplemental Materials.) A behavior was assessed as culturally infeasible if we found it to conflict with prevailing values and social mores of the majority of U.S. residents. For ecological applicability, certain 
habitats, such as tropical forests, do not exist in the United States, and therefore could not be considered for intervention. Finally, if current laws or regulations would actively undermine the promotion of a given behavior, the behavior was excluded. We filtered for behaviors with medium or high emissions impact and that met all three criteria for U.S. relevance, to arrive at a list of eight possible interventions.

\section{Table 1: Shortlist of Interventions Considered}

We conducted a literature review and interviewed 20 subject matter experts, identified based on their expertise in the eight shortlisted behaviors, to surface the underlying social, behavioral, and psychological mechanisms driving those behaviors and the applicability of various behavior change techniques. Our research indicated that the residential energy use behaviors on our shortlist shared common pathways to both action and emissions reduction, which led us to bundle them and model them as a single behavior. The output of this analysis is a final list of six behavioral pathways to reducing emissions that, compared to the initial set of all identified behaviors, are highly U.S. relevant and have a high or moderately high emissions reduction potential:

- Purchase an Electric Vehicle (EV): New car buyers opt for an electric vehicle

- Reduce Air Travel: High-frequency fliers fly one fewer time per year

- Eat a Plant-Rich Diet: Anyone who is not already vegetarian eats a bit less meat*

- Offset Carbon: Individuals offset their full annual emissions with verified carbon credits

- Reduce Food Waste: Households reduce food waste by $20 \%$

- Purchase Green Energy: Households install solar energy and water heating and meet any additional energy needs with renewable energy

*eats like the next-lowest meat consuming quintile of Americans, defined in more detail below.

\section{Modeling Behaviors}

To estimate the annual mitigation impact for a change in each of the behaviors listed above, we built a model that compares business as usual (BAU) trajectories with behavior change scenarios. BAU scenarios are based on linear extrapolations of historic trends (i.e., 1990-2018), and behavior change scenarios assume immediate adoption of carbon-footprint reducing activities. Our results should therefore be read as indicative rather than predictive. The model does not account for the potential indirect effects of climate-friendly behavior adoption.

We modeled adoption rates (i.e., the number of individuals who change their behavior) with a twostep approach. First, we estimated the addressable market for each behavior, which we defined as the number of individuals or households that are in the position to, but have not yet adopted, a certain behavior. (See Supplemental Materials for more details on addressable markets.) Second, we assumed that $10 \%$ of this addressable market adopts the behavior. Past meta-analyses have found varying degrees of effectiveness in behavior change interventions, ranging from 1.4\% for minimal "nudge" style interventions to $18.1 \%$ for broad environmental social marketing campaigns, to $27.2 \%$ for interventions that change the default consequence of inaction. ${ }^{9,10,11}$ Due to the wide range of adoption rates achieved across different types of interventions, the ultimate adoption rate of any of these behaviors will depend on the intervention chosen, so these rates of adoption should be interpreted as illustrative and can be linearly adjusted depending on the changes expected from specific interventions and contexts. For purchasing carbon offsets, we assumed only a 5\% adoption rate, due to offset 
markets not being mature enough to absorb the demand for carbon credits that would result from $10 \%$ adoption.

We modeled each behavior as per the below assumptions.

Purchase Electric Vehicle: We modeled Vehicle Miles Traveled (VMT) in EVs when the share of passenger vehicular travel completed in EVs was increased by $10 \%$. Though gains in efficiency in the U.S. grid mix could vary significantly, for modeling purposes we projected linear efficiency gains after 2017 based on a 10-year average. While this linear assumption makes modeling easier to interpret and acknowledges the change expected over time, future work may refine these projections to account for further case-specific assumptions. Wheel-to-well emission factors for gasoline were assumed to remain static, though passenger vehicle fuel economy was projected to increase, based on data from the U.S. Annual Energy Outlook and the Bureau of Transportation Statistics. ${ }^{12,13}$

Reduce Air Travel: We defined frequent fliers as those U.S. residents who take 5 or more flights per year $(13 \% \text { of Americans })^{14}$ and assumed that individuals in this segment of frequent fliers take one fewer transnational or transatlantic flights per year ( 2,550 miles equivalent to $0.9 \mathrm{MtCO} 2 \mathrm{e}) .{ }^{15}$ Our business as usual scenario assumed an industry-wide decreasing emissions intensity.

Eat a Plant-Rich Diet: Based on research by Heller et al. (2018), we split U.S. residents into five quintiles of increasing levels of meat consumption, with people in the fifth quintile consuming the most meat and thus having the highest carbon emissions. ${ }^{16} \mathrm{We}$ assumed that $10 \%$ of people across all but the first quintile switched to the diet of the next less meat-heavy quintile. To calculate GHG emissions reductions, we used the midpoint GHG emissions factor of each quintile.

Offset Carbon: Our model assumed that purchasing offsets is equivalent to eliminating emissions. ${ }^{1}$ It assumed that individuals who purchase offsets opt to offset their entire annual carbon footprints and that their footprint is the U.S. average emission intensity. As stated above, we assumed that only $5 \%$ of U.S. residents offset their emissions. We assumed average per capita annual emissions of 16 MtCO2e, based data from the World Bank. ${ }^{17}$

Reduce Food Waste: Evidence suggests that interventions such as plate size reduction can reduce food waste by approximately $20 \% .^{18}$ We therefore modeled emissions reductions associated with a $20 \%$ reduction in per-person household food waste. We assume that the change in consumption creates a change in demand such that emissions are reduced throughout the food supply chain (production, transport, storage, etc.).

Purchase Green Energy: We modeled a fully emission-neutral energy mix through a combination of rooftop solar installation, solar water heating, and green energy purchasing. Our model assumed independent adoption between these interventions - which is to say that our model did not assume that the population of rooftop solar adopters was more likely to be the population purchasing green energy. Energy consumption emissions capture residential space heating and cooling, lighting, water heating, cooking, and appliances. For water heating, the model assumed that $100 \%$ can be offset with solar. Our business as usual scenario assumed normal improved efficiency of residential energy use,

\footnotetext{
${ }^{1}$ While certified carbon credits are verified for additionality, it is possible that not all offset credits are additional and furthermore that this equivalency can be debated depending on project type. This assumption may be adjusted by multiplying the impact by intervention-specific expected effectiveness.
} 
in accordance with the IECC code for new buildings. Our model held constant the share of buildings eligible for rooftop solar (75\%) and the percentage of energy displaced through 2040.

The model source data are largely based on observed behavioral metrics and administrative data. However, diet composition, flying behavior, and green energy purchasing prevalence are derived from nationally representative surveys, which should be interpreted with the understanding that these selfreports can be biased. Please see Supplemental Materials for model supporting data sources and calculations.

\section{Results \& Policy Opportunities to Accelerate Behavior Change}

Our model indicates that a 10\% increase in adoption in the addressable market for each behavior (and a 5\% increase for carbon credit purchasing) would reduce U.S. emissions by 464 MtCO2e annually and close our Paris Agreement shortfall by $76 \%$ by 2025 . Having an impact on emissions at the national scale via behavior change alone would be a great achievement and behaviorally informed policies have a key role to play.

\section{Figure 1: Behavior Adoption and the U.S. Paris Emissions Gap}

As has been recognized by the more than 100 governments and institutions that have commissioned 'behavioral insights teams' or 'nudge units,' behaviorally-informed policy has incredible potential to efficiently drive behavior adoption. ${ }^{19,20}$ Below, for each behavior, we provide its potential emissions mitigation impact based on our modeled adoption rate, the avoided cost to society of that emissions reduction, and example behavioral insights from the literature that could inform policy design towards achieving adoption of that behavior. ${ }^{2}$ Of course, the realized rate of adoption of a given policy in practice will depend on design and implementation.

\section{Behavior: Purchase an electric vehicle}

Change Modeled: $10 \%$ of new car purchases are EVs

Emissions Mitigation Impact: 65 million tons of carbon dioxide equivalent (MtCO2e) annually

Avoided Cost to Society (Social value of mitigation): $\$ 2.9$ to $\$ 33.4$ billion per year ${ }^{21,22}$

Illustrative Behavioral Insights for Policy:

Hyperbolic Discounting: People tend to pay too much attention to present costs and benefits while ignoring those in the future, a phenomenon known as hyperbolic discounting. ${ }^{23}$ Many current policies intended to increase EV adoption are based on tax credits, which the buyer only benefits from months after purchase. Hyperbolic discounting predicts that these incentives could be far more effective, even at lower cash values, if brought into the present and provided at time of purchase. One possible mechanism for doing this while also giving EV markets development runway would be by providing vouchers to subsidize preliminary contracts to buy or lease EVs that can be used within 1-2 years.

\footnotetext{
2 Avoided cost to society calculated using social cost of carbon estimates from the EPA (2017) on the low end and from
} Ricke et al. (2018) on the high end. 
Simplification: Complex processes add cognitive costs to a decision. Removing this complexity through simplification can increase interest and enrolment in voluntary programs. ${ }^{24}$ Current EV incentive policies are often complex, based on multiple factors like consumer income, engine size, or comparable non-electric vehicles. ${ }^{25}$ This complexity allows for precision targeting, but is also difficult to cognitively process. Simpler schemes would remove the friction created by such calculations for both dealers and buyers, and therefore likely increase adoption.

\section{Behavior: Reduce air travel}

Change Modeled: 10\% of frequent fliers drop one long haul flight per year

Emissions Mitigation Impact: $4 \mathrm{MtCO} 2 \mathrm{e}$ annually

Avoided Cost to Society: $\$ 0.2$ to $\$ 2.1$ billion per year

Illustrative Behavioral Insight for Policy:

Salience: When making decisions, people place more weight on whatever attribute they are momentarily focused on, that is, a bias towards salient information. ${ }^{26}$ However, the environmental consequences of air travel are rarely salient when deciding whether to travel. Policymakers can prompt that salience through interventions like mandating emotionally compelling labeling at the point of purchase indicating the pollution effect of flying, similar to the cigarette labeling that has successfully reduced smoking, or indicating peer norms around decreased flying. ${ }^{27}$ The U.S. government already requires that all federally-funded travel use a U.S. airline, demonstrating a willingness to direct flying behavior. A more targeted approach to reducing air travel could be to require those traveling using state or federal funds to justify for supervisor approval why the trip is required over alternatives such as video conferencing, and why less carbon-intensive travel modes such as rail are infeasible. While not outright prohibiting flying, requiring justification prompts consideration of alternatives, likely increasing their uptake.

\section{Behavior: Eat a plant-rich diet}

Change Modeled: 10\% of meat-eaters drop down one consumption quintile.

Emissions Mitigation Impact: $25 \mathrm{MtCO} 2 \mathrm{e}$ annually

Avoided Cost to Society: $\$ 1.1$ to $\$ 12.7$ billion per year

Illustrative Behavioral Insight for Policy:

Information: Providing information can be an effective tactic for shifting behavior, particularly when it differs from preconceived beliefs and relates to preexisting values ${ }^{28}$ Consumers have been shown to substantially underestimate the climate impact of their food choices, and particularly the impact of meat. ${ }^{29}$ While policymakers have significant power in food labeling, this power has primarily been used to provide health-related information. However, when this authority has been redirected to labeling based on emissions impact, it has influenced consumers, driving a reduction in the purchase of highemitting foods. ${ }^{30}$ Mandating the inclusion of such labels would help consumers make more informed decisions while reducing meat consumption, as has been incorporated into Denmark's plan to become carbon neutral by $2050 .{ }^{31}$

\section{Behavior: Offset carbon}

Change Modeled: $5 \%$ of U.S. residents offset their emissions

Emissions Mitigation Impact: $276 \mathrm{MtCO} 2 \mathrm{e}$ annually

Avoided Cost to Society: $\$ 12.4$ to $\$ 142.6$ billion per year

Illustrative Behavioral Insights for Policy: 
Defaults and Active Choice: People often choose the option to which they were defaulted into, meaning the outcome that occurs if they make no proactive choice. ${ }^{32}$ Behavioral scientists have developed two strategies that leverage this bias. The first is making the choice active, where the actor must deliberately choose one option or the other. The second is swapping which outcome occurs by default. ${ }^{33}$ Presently, purchasing carbon offsets is generally an "opt-in" decision, in which purchasing offsets requires a consumer to actively seek them out. As an alternative, a policy could shift this to an active choice by mandating the offering of carbon offsets by consumer-facing emitters such as airlines. A policy could take such a scheme one step further by defaulting customers into purchasing offsets, which has been shown to increase offset purchasing while preserving customer choice. ${ }^{34}$

\section{Behavior: Reduce food waste}

Change Modeled: $10 \%$ of households reduce food waste by $20 \%$

Emissions Mitigation Impact: $13 \mathrm{MtCO} 2 \mathrm{e}$ annually

Avoided Cost to Society: $\$ .6$ to $\$ 5.3$ billion per year

Illustrative Behavioral Insights for Policy:

Information: People's beliefs, particularly concerning their health and safety, can substantially influence their choices. ${ }^{35}$ Providing information can inform these beliefs and therefore behavior. The primary reason reported by consumers for discarding food was concern about foodborne illness. ${ }^{36}$ While $91 \%$ of Americans report paying attention to date labels (i.e. "best by," "use by," and "sell by"), a majority do not realize these labels are not federally regulated, potentially leading to over-reliance on labels. ${ }^{37}$ Whether deliberately designed to misinform or not, the present labeling regime results in less wellinformed consumers wasting more food. Recognizing that consumers heavily rely on date labels, policymakers have an opportunity to provide guidance for and regulation of such labels, rather than relying on producers with mixed incentives to provide accurate information. ${ }^{38}$

\section{Behavior: Purchase green energy}

Change Modeled: A 10\% increase in households using 100\% renewable energy from a combination of rooftop solar and green energy purchasing and solar water heating

Emissions Mitigation Impact: $82 \mathrm{MtCO} 2 \mathrm{e}$ annually

Avoided Cost to Society: $\$ 4$ to $\$ 42$ billion per year

Illustrative Behavioral Insights for Policy:

Simplification: Adding complexity to a decision increases the psychological cost, leading consumers to often simply prefer not to choose at all. ${ }^{39}$ In the case of rooftop solar, choosing not to choose effectively preserves the status quo of relying on grid-based energy. A major barrier to purchasing rooftop solar is complexity, much of which is due to policy around permitting, inspection, and interconnection to put energy back into the grid. ${ }^{40}$ Policy reform could lessen this friction through various streamlining tactics, including providing access to web-based permitting.

Defaults: Changing the default option that results when someone chooses not to choose is particularly impactful in those domains where people are likely not paying significant attention to their options. This is the case when selecting an energy provider from a utility. In this context, switching utility customers to a green energy provider has been successfully supported through policy by defaulting customers into green energy, driving adoption rates as high as $94 \% .{ }^{41}$ 


\section{The Path Forward}

Policymakers looking to help constituents reduce emissions have many options for behaviors on which to focus and a limited timeframe in which to act. Our analysis allows for a conscientious allocation of resources and focused intervention by identifying the highest impact individual behaviors for the United States context. Importantly, varying interests and capacities among different U.S. populations may make certain of these six behaviors more or less relevant for a given group. Policymakers are encouraged to see these behaviors and illustrative behavioral insights as springboards from which to conduct their own analysis specific to their context. This likely includes a combination of qualitative and quantitative research to identify which of these behaviors may be most suitable for that population, and what behaviorally informed policies might most effectively motivate adoption. This design process should involve multi-stakeholder dialog, including active participation from community members as well as behavioral and policy experts. Such behaviorally informed policies targeting high impact behaviors present an opportunity to provide a much-needed boost to emissionsreducing individual and household behaviors and could be key to achieving critical near-term emission reductions that mitigate global climate change.

${ }^{1}$ IPCC, 2018: Global Warming of $1.5^{\circ} \mathrm{C}$. An IPCC Special Report on the impacts of global warming of $1.5^{\circ} \mathrm{C}$ above preindustrial levels and related global greenhouse gas emission pathways, in the context of strengthening the global response to the threat of climate change, sustainable development, and efforts to eradicate poverty [Masson-Delmotte, V., P. Zhai, H.-O. Pörtner, D. Roberts, J. Skea, P.R. Shukla, A. Pirani, W. Moufouma-Okia, C. Péan, R. Pidcock, S. Connors, J.B.R. Mathews, Y. Chen, X. Zhou, M.I. Gomis, E. Lonnoy, T. Maycock, M. Tignor, and T. Waterfield (eds.)]. In Press.

2 Sunstein, C. R. (2016). The ethics of influence: Government in the age of behavioral science. Pp. 134-135. Cambridge University Press.

${ }^{3}$ Sunstein, C. R. (2016). Do people like nudges. Admin. L. Rev., 68, 177.

${ }^{4}$ Kingdon, J. W., \& Stano, E. (1984). Agendas, alternatives, and public policies (Vol. 45, pp. 165-169). Boston: Little, Brown.

5 https://climateactiontracker.org/countries/usa/

${ }^{6}$ Dietz, T., Gardner, G. T., Gilligan, J., Stern, P. C., \& Vandenbergh, M. P. (2009). Household actions can provide a behavioral wedge to rapidly reduce US carbon emissions. Proceedings of the National Academy of Sciences, 106(44), 1845218456.

7 Wynes, S., \& Nicholas, K. A. (2017). The climate mitigation gap: education and government recommendations miss the most effective individual actions. Environmental Research Letters, 12(7), 074024.

8 https://www.drawdown.org/solutions/table-of-solutions.

${ }^{9}$ DellaVigna, S., \& Linos, E. (2020). RCTs to Scale: Comprehensive Evidence from Two Nudge Units. Working Paper, UC Berkeley.

${ }^{10}$ Green, K. M., Crawford, B. A., Williamson, K. A., \& DeWan, A. A. (2019). A meta-analysis of social marketing campaigns to improve global conservation outcomes. Social Marketing Quarterly, 25(1), 69-87.

11 Jachimowicz, J. M., Duncan, S., Weber, E. U., \& Johnson, E. J. (2019). When and why defaults influence decisions: A meta-analysis of default effects. Behavioural Public Policy, 3(2), 159-186.

12 U.S. Energy Information Administration, Annual Energy Outlook 2018 (Feb. 6, 2018), https://www.eia.gov/outlooks/aeo/pdf/AEO2018.pdf.

${ }^{13}$ https://www.bts.gov/content/average-fuel-efficiency-us-light-duty-vehicles 
${ }^{14}$ Heimlich, J.P. and Chris Jackson (2018). Air Travelers in America: Findings of a Survey Conducted by Ipsos [PowerPoint slides]. Retrieved from http://airlines.org/wp-content/ uploads/2018/02/A4A-AirTravelSurvey20Feb2018-FINAL.pdf

${ }^{15}$ Schlossberg, T. (2017, July 27). Flying Is Bad for the Planet. You Can Help Make It Better. New York Times. Retrieved from: www.nytimes.com

${ }^{16}$ Heller, M. C., Willits-Smith, A., Meyer, R., Keoleian, G. A., \& Rose, D. (2018). Greenhouse gas emissions and energy use associated with production of individual self-selected US diets. Environmental Research Letters, 13(4), 044004. https://doi. org/10.1088/1748-9326/aab0ac

${ }^{17}$ https://data.worldbank.org/indicator/en.atm.co2e.pc

${ }_{18}$ B-HUB. Smaller Plate, Less Waste. (n.d.). Retrieved December 6, 2018: http://www.bhub.org/project/smaller-plateless-waste/

${ }_{19}$ Policymakers around the world are embracing behavioural science. (2017). The Economist. Retrieved from: https://www.economist.com/ international/2017/05/18/policymakers-around-the-world-are-embracingbehaviouralscience

${ }^{20}$ OECD, 2017. Behavioral Insights and Public Policy: Lessons from around the world. OECD Publishing, Paris. http://dx.doi.org/10.1787/9789264270480-en

21 https://19january2017snapshot.epa.gov/climatechange/social-cost-carbon .html

22 Ricke, K., Drouet, L., Caldeira, K., \& Tavoni, M. (2018). Country-level social cost of carbon. Nature Climate Change, 8(10), 895-900. https://doi.org/10.1038/s41558-018-0282-y

${ }^{23}$ Laibson, D. (1997). Golden eggs and hyperbolic discounting. The Quarterly Journal of Economics, 112(2), 443-478. https://doi.org/10.1162/003355397555253

24 Sunstein, C. R. (2014). Nudging: a very short guide. Journal of Consumer Policy, 37(4), 583-588.

25 Yang, Z., Slowik, P., Lutsey, N., \& Searle, S. (2016). Principles for effective electric vehicle incentive design. Internatnional Council Clean Transportation June.

${ }^{26}$ Kahneman, D., Slovic, S. P., Slovic, P., \& Tversky, A. (Eds.). (1982). Judgment under uncertainty: Heuristics and biases. Cambridge university press. Pg. 192.

${ }^{27}$ Azagba, S., \& Sharaf, M. F. (2013). The effect of graphic cigarette warning labels on smoking behavior: evidence from the Canadian experience. Nicotine \& Tobacco Research, 15(3), 708-717. https://doi.org/10.1093/ntr/nts194

${ }^{28}$ Michie, S., Van Stralen, M. M., \& West, R. (2011). The behaviour change wheel: a new method for characterising and designing behaviour change interventions. Implementation science, 6(1), 42.

${ }^{29}$ Hartmann, C., \& Siegrist, M. (2017). Consumer perception and behaviour regarding sustainable protein consumption: A systematic review. Trends in Food Science \& Technology, 61, 11-25.

${ }^{30}$ Camilleri, A. R., Larrick, R. P., Hossain, S., \& Patino-Echeverri, D. (2019). Consumers underestimate the emissions associated with food but are aided by labels. Nature Climate Change, 9(1), 53-58. https://doi.org/10.1038/s41558-0180354-z

${ }^{31}$ Denmark to label food according to effect on climate. (2018, October 8). Retrieved from: https://www.thelocal.dk/20181008/denmark-to-mark-food-according-to-effect-on-climate

32 Jachimowicz, J. M., Duncan, S., Weber, E. U., \& Johnson, E. J. (2019). When and why defaults influence decisions: A meta-analysis of default effects. Behavioural Public Policy, 3(2), 159-186.

${ }^{33}$ Keller, P. A., Harlam, B., Loewenstein, G., \& Volpp, K. G. (2011). Enhanced active choice: A new method to motivate behavior change. Journal of Consumer psychology, 21(4), 376-383.

34 Székely, Nadine; Weinmann, Markus; and vom Brocke, Jan. (2016) Nudging People to Pay CO2 Offsets - The effect of anchors in flight booking processes. Research-in-Progress Papers. 62. https://aisel.aisnet.org/ecis2016 rip/62 
35 Thaler, R. H., \& Sunstein, C. R. (2009). Nudge: Improving decisions about health, wealth, and happiness. Penguin. Pg. 189

${ }^{36}$ Neff, R. A., Spiker, M. L., \& Truant, P. L. (2015). Wasted food: US consumers' reported awareness, attitudes, and behaviors. PloS one, 10(6), e0127881. https:/ / doi.org/10.1371/journal.pone.0127881

${ }^{37}$ Neff, R. A., Spiker, M., Rice, C., Schklair, A., Greenberg, S., \& Leib, E. B. (2019). Misunderstood food date labels and reported food discards: A survey of US consumer attitudes and behaviors. Waste management, 86, 123-132.

https://doi.org/10.1016/j.wasman.2019.01.023

38 https://www.refed.com/solutions/standardized-date-labeling/

${ }^{39}$ Iyengar, S. S., \& Lepper, M. R. (2000). When choice is demotivating: Can one desire too much of a good thing?. Journal of personality and social psychology, $79(6), 995$.

40 https://www.ncsl.org/research/energy/solar-policy-toolbox.aspx

${ }^{41}$ Sunstein, C. R., \& Reisch, L. A. (2014). Automatically green: Behavioral economics and environmental protection. Harv. Envtl. L. Rev., 38, 127. https://dash.harvard.edu/handle/1/16217276 
Table 1: Shortlist of Interventions Considered

\begin{tabular}{ll}
\hline Commute and travel & Electric vehicles \\
\cline { 2 - 2 } & Reduce air travel \\
\hline Lifestyle & Plant-Rich Diet \\
\hline Waste reduction \& management & Reduced Food Waste \\
\hline Residential energy use & Rooftop Solar \\
\hline & Buy green energy \\
& Solar water heaters \\
\end{tabular}

Figure 1: Behavior Adoption and the U.S. Paris Emissions Gap

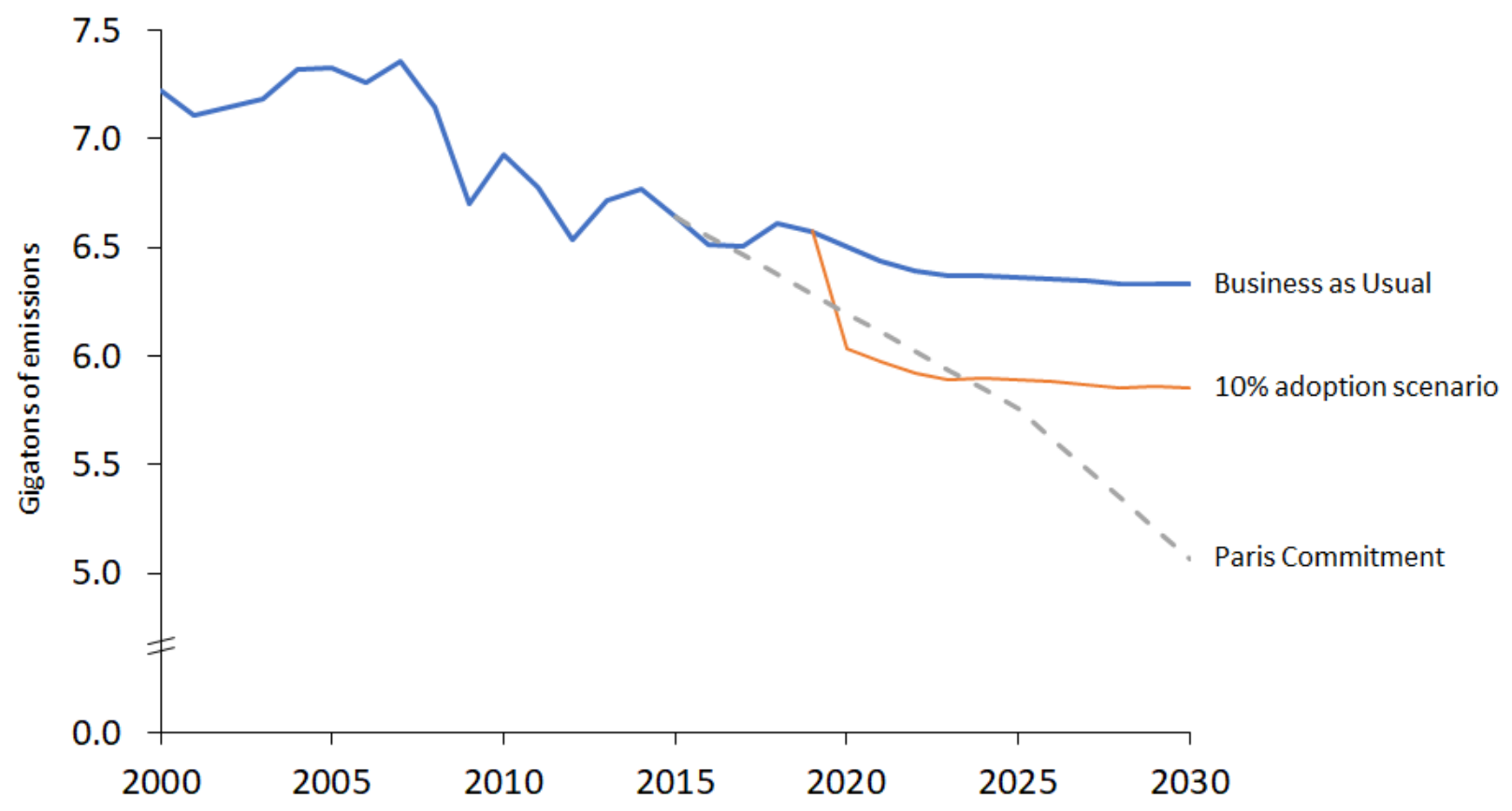

